\title{
Exploratory study of the effectiveness of a professional development program on the academic achievement and classroom behavior of students with Fetal Alcohol Spectrum Disorder in British Columbia, Canada
}

\author{
Erica Clark ${ }^{1,2}$, M. Anne George ${ }^{1,3,4}$, Cindy Hardy ${ }^{4}$, Wendy A. Hall ${ }^{1}$, Peter D. MacMillan ${ }^{4}$, Stacey Wakabayashi ${ }^{5}$, \\ and Kathleen Hughes ${ }^{5}$
}

${ }^{1}$ University of British Columbia, Vancouver, BC, Canada

${ }^{2}$ Huron County Health Unit, Clinton, ON, Canada

${ }^{3}$ Child \& Family Research Institute, Vancouver, BC, Canada

${ }^{4}$ University of Northern British Columbia, Prince George, BC, Canada

${ }^{5}$ School District No. 57, Prince George, BC, Canada

\begin{abstract}
Aim: Exploratory assessment of a professional development program for teachers supporting students with Fetal Alcohol Spectrum Disorder (FASD).

Design: A mixed-method research design, using qualitative descriptive and quasi-experimental methods, was employed.

Setting: The study occurred in selected public elementary schools in a British Columbia school district.

Participants: Elementary school teachers and students with FASD.

Measures: For the quasi-experimental component, the Behavior Assessment System for Children, 2nd edition (BASC-2) Teacher Rating Scale (TRS), and Student Observation System assessed classroom behavior. The Curriculum-Based Measure (CBM) assessed reading, writing, and mathematics skills of children with FASD. Inductive thematic analysis was used to derive themes from teachers' interviews.

Findings: A statistically significant improvement in intervention students' classroom behavior was observed. An improvement of moderate effect size was seen for academic achievement, although the changes were not statistically significant. Teachers reported that the professional development program changed their teaching practice. Intervention teachers described how they redefined students' behaviors and adapted their teaching practice to accommodate students' neurological deficits.
\end{abstract}

Conclusions: The results provide preliminary support for the effectiveness of the professional development program for elementary school teachers teaching students with FASD. Further research is needed with a larger sample size to reduce type II error.

The Provincial Outreach Program for Fetal Alcohol Spectrum Disorder (POPFASD) (http://www.fasdoutreach. ca) in British Columbia (BC), Canada, is unique in offering a professional development (PD) program for teachers that focuses on changing the classroom environment to meet the unique needs of students with FASD. Our study provides preliminary evidence of the effectiveness of the PD program. Fetal Alcohol Spectrum Disorder (FASD) is an umbrella term used to describe the spectrum of effects that may result from prenatal alcohol exposure (Chudley et al., et al., 2005). FASD is estimated to have a prevalence rate of one percent of Canadian students (Burstyn, Sithole, \& Zwagenbaum, 2010; Health Canada, 2002).

Pianta and Walsh's (1996) contextual systems model provides a framework for understanding the effects of cognitive challenges experienced by students with FASD on classroom behavior and academic achievement. According to the model, children react as open, dynamic systems that interact with and respond to the people and resources in their environments (Pianta \& Walsh, 1996).

Correspondence: Erica Clark, Health \& Library Complex, 77722B London Road, RR\#5, Clinton, Ont, N0M 1L0. Telephone: 519-482-3416 ext. 2022. Fax: 519-4827820. Email: eclark@huroncounty.ca

Financial support: Victoria Foundation FASD Action Fund

Declaration of interest: There are no conflicts of interest.

Keywords: fetal alcohol spectrum disorder, intervention, children, elementary school teachers, professional development 
The quality of the relationships; the fit between environments, people and resources; and the cognitive, behavioral, and neurodevelopmental skills of children influence children's behavior over time (Pianta \& Walsh, 1996). Students with FASD may experience one or more cognitive challenges, including slower information processing speed (Burden, Jacobson, \& Jacobson, 2005), learning and memory difficulties (Kaemingk \& Halverson, 2000; Mattson \& Roebuck, 2002), and attention (Streissguth, Barr, Sampson, \& Bookstein, 1994) and working memory deficits (Streissguth, Barr, \& Sampson, 1990). There is no typical profile associated with FASD (Burden, Jacobson, Sokol, \& Jacobson, 2005; Kable \& Coles, 2004; McGee, Fryer, Bjorkquist, Mattson, \& Riley, 2008). A child may have deficits in information processing speed and working memory that make thinking about several instructions at one time difficult and impede rapid reaction to instructions. The teacher-student relationship may be negatively affected if the teacher reprimands a student for slow reaction to instructions. Over time, the student may disengage from his or her school work and experience a deteriorating relationship with that teacher. Our hypothesis is that adapting the classroom environment will improve students' behavior, resulting in more opportunities for learning.

Existing literature on interventions for children with FASD indicates increased success through adaptations to children's classroom and home environments (Bertrand, 2009; Malbin, 2006). Three programs targeted parents (Bertrand, 2009), while the fourth included parents and teachers (Malbin, 2006). Behavior was redefined as a neurodevelopmental disability, rather than willful disobedience, and parents and teachers were taught to change their responses and prevent situations that triggered problem behavior (Bertrand, 2009). In summary, these studies support the hypothesis that changes to the environments of students with FASD may improve behavior.

POPFASD developed a PD program based on the contextual systems model to support educators teaching students with FASD. POPFASD staff implemented the PD program over a school year; it included two full-day and four half-day workshops and weekly mentor-teacher meetings. At the initial two-day workshop, teachers received an overview of FASD and completed the Know Learn and Need to Know (KLN) and Learner Environment Instruction Curriculum (LEIC) forms, using information from school files and the teachers' experiences with their students. The information in the files, including previous assessments, varied between students. The KLN and LEIC forms helped teachers organize information, prompted them to search for more information, and identified potential accommodations based on students' strengths. The four half-day workshops included presentations on FASD, psychology, occupational therapy, and speech and language therapy, as well as more planning of accommodations for students with FASD. The LEIC and KLN forms and details on workshop content are available from POPFASD.
This study aimed to answer the following questions:

1. Do teachers perceive the professional development program as affecting their abilities to adapt the classroom environment for students with FASD?

2. Is the professional development program associated with changes in teachers' perceptions of classroom behavior of students with FASD?

3. Is the professional development program associated with changes in students with FASD's classroom behavior, observed by researchers?

4. Is the professional development program associated with improved ability to complete grade-appropriate reading, writing, and math curriculum amongst students with FASD?

The PD program was administered to teachers, who applied the training in a non-uniform manner to their students with FASD. Outcomes of interest were students' classroom behavior and academic achievement.

\section{Methods}

This study used a mixed-methods research design (Green, Caracelli, \& Graham, 1989) that combined quasiexperimental methods (Cook \& Campbell, 1979) with qualitative descriptive methods (Sandelowski, 2000).

\section{Quasi-experimental design}

Students' behavior and academic achievement were measured pre-, mid-, and post-intervention in the intervention and untreated comparison groups.

\section{Measures}

The Curriculum-Based Measure (CBM) was used to assess reading, writing, and mathematics skills. The CBM maintains strong test-retest and inter-rater reliability and good concurrent, criterion-related and predictive validity, and reflected curriculum taught in the school district where the study was undertaken (Fewster \& MacMillan, 2002; Hintz, Shapiro, Conte, \& Basile, 1997; McMaster \& Espin, 2007; Wayman, Wallace, Wiley, Ticha, \& Espin, 2007). Two research assistants blind to group membership administered the CBM.

The Behavior Assessment System for Children, 2nd edition (BASC-2) Teacher Rating Scale (TRS), a self-report survey completed by teachers, assessed teachers' perceptions of students' classroom behavior. The BASC-2 TRS has demonstrated adequate test-retest reliability and construct and criterion-related validity, and focuses on positive and negative attributes of student behavior (Reynolds \& Kamphaus, 2004; Tan, 2007).

The BASC-2 Student Observation System (SOS) assesses observed positive and negative classroom behavior using momentary time sampling (Reynolds \& Kamphaus, 2004). The BASC-2 SOS was administered by a research assistant blind to group membership. 


\section{Analysis}

Analysis utilized the $t$-test for pre-intervention between group differences, and Friedman's test with post-hoc analysis for within-group change over time (Siegel \& Castellan, 1988). Alpha $(\alpha)$ was set at .10 to increase the power to detect significant findings and lower the risk of type II errors (Ellis, 2010). All statistical analysis used SPSS version 19.0. Effect size calculations were completed for intervention group pre- to post-intervention (Morris \& DeShon, 2002; equation 13). According to Wolfe (1986), an effect size greater than .50 indicates educational significance.

\section{Qualitative descriptive design}

Inductive thematic analysis was undertaken on verbatim transcripts of teachers' semi-structured interviews. The interview questions (Clark, 2012, p. 232) asked teachers to describe their perceptions of students' behavior and strategies for accommodating students' needs. The analysis employed an inductive approach, using descriptive and pattern coding (Miles \& Huberman, 1994). Teachers were engaged in member checking to support credibility of the results (Guba \& Lincoln, 1989).

\section{Recruitment}

Elementary schools were eligible if they did not have a concurrent FASD intervention. A teacher was eligible if her principal consented and she had at least one eligible student in her classroom. A student was eligible if she or he was diagnosed with Fetal Alcohol Syndrome (FAS), partial FAS, or Alcohol Related Neurodevelopmental Disorder by a medical doctor, and her or his teacher consented to participate.

Recruitment of teachers and students was undertaken using two strategies. Initially, teachers in eligible elementary schools were recruited for the study. After a teacher consented to participate, caregivers were contacted to determine if any students were eligible. In the second strategy, a local pediatrician mailed consent forms and information letters to the caregivers of students she had diagnosed. Teachers were recruited after caregivers and children consented to participation. Intervention and comparison-group teachers were also recruited for the qualitative component.

\section{Ethics}

Approvals were obtained from the University of British Columbia Behavioural Research Ethics Board and the University of Northern British Columbia Research and Ethics Board. All participants provided informed consent or assent.

\section{Results}

\section{Participants}

Fifteen teachers from eight elementary schools were recruited, and 12 teachers from seven schools agreed to participate. Participating teachers' experience ranged from 15 to 32 years, with a mean of 22 years. All participating teachers were female and Caucasian. Ten teachers taught primary classrooms and two taught intermediate classrooms.

Twenty-two students were recruited for the study; 13 were eligible to participate. Exclusion occurred at the school, classroom, and student level. One school was excluded because it was conducting a concurrent FASD intervention ( $N=5$ students). Three teachers declined to participate because they were not interested or too busy, which excluded their students $(N=3)$. One student did not have a medical diagnosis. The nine excluded students did not differ significantly from eligible students (see Table 1).

Table 1

Demographics of all students recruited, $N=22$

\begin{tabular}{|c|c|c|c|c|c|}
\hline Independent variable & $\begin{array}{l}\text { Eligible students } \\
\qquad(N=13)\end{array}$ & $\begin{array}{l}\text { Excluded students } \\
\qquad(N=9)\end{array}$ & $\begin{array}{c}\text { Degrees of freedom } \\
(v)\end{array}$ & $\begin{array}{c}t \text {-Test } \\
\text { statistic }\end{array}$ & Two-tailed $p$ \\
\hline \multicolumn{6}{|l|}{ Age } \\
\hline Range & 6-12 years & 6-12 years & 20 & 0.51 & 0.62 \\
\hline Mean & 7.9 years & 7.8 years & & & \\
\hline \multicolumn{6}{|l|}{ Ethnicity } \\
\hline Aboriginal & $62 \%$ & $89 \%$ & 20 & -1.53 & 0.14 \\
\hline Caucasian & $38 \%$ & $11 \%$ & & & \\
\hline \multicolumn{6}{|l|}{ Gender } \\
\hline Male & $77 \%$ & $67 \%$ & 20 & -0.22 & 0.83 \\
\hline Female & $23 \%$ & $33 \%$ & & & \\
\hline
\end{tabular}


Participating students were diagnosed with FAS by the same pediatrician, using Gestalt diagnostic guidelines (Sokol \& Clarren, 1989). Sixty-nine percent of students were in foster care; the remainder lived with their biological families.

Six teachers and seven students were allocated to the intervention group and six teachers and six students to the comparison group. Students, but not teachers, were blinded to the intervention. Students and teachers were allocated by assigning one student-teacher dyad to the comparison group, randomizing the remaining participants, and reassigning student-teacher dyads to match as closely as possible for student age, gender, and school report of disruptive behavior. Experimental groups were not equivalent (see Table 2), and students and teachers were lost to follow-up (see Figure 1). The intervention group scored significantly higher, indicating greater challenges, on Percent Observed Problem Behavior $(v=10, t=2.17, p$ $=.06)$, Behavioral Symptoms Index $(v=10, t=2.09, p=$ $.10)$, and Externalizing Problems $(v=10, t=3.57, p=.01)$ Scales.

Three students were lost to follow up ( $N=2$ intervention and $N=1$ comparison groups) and five students experienced major changes in their home environments $(N$ $=4$ intervention and $N=1$ comparison groups) (see Figure 1). Changes included increased or new visits with a birth parent, new foster homes, and preparations to move.
Changes occurred at mid- and post-intervention ( $N=2$ and $N=3$, respectively).

\section{Pre- and post-intervention changes}

Measures were obtained of students' classroom behavior and academic achievement pre-, mid-, and postintervention. Statistically significant differences were observed between pre- and post-intervention for the intervention group only: BASC-2 TRS Adaptive Skills ( $v=$ $\left.4, \chi^{2}=7.60, p=.02\right)$ and School Problems $\left(v=4, \chi^{2}=6.40\right.$, $p=.04$ ) (see Table 3 ). No statistically significant differences were observed for the comparison group (see Table 3). The Adaptive Skills scale measures emotional expression and daily living, communication, and study skills, while School Problems measures motivation, attention, learning, and cognition (Reynolds \& Kamphaus, 2004). Attention, learning, motivation, cognition (School Problems Scale), and adaptive behavior (Adaptive Skills Scale), as assessed by the BASC-2 TRS are important skills contributing to students' success in school (Reynold \& Kamphaus, 2004). Post-hoc analysis indicated a pre- to mid-intervention increase for the BASC-2 TRS Adaptive Skills (see Figure 2; mean rank difference $=1.5, z=1.34, p$ $=.09$ ) and decrease for School Problems Scale (see Figure 3 and Table 4); mean rank difference $=1.60, \mathrm{z}=1.34, p=$ .09 ). The effect size for the intervention group was greater than .50 for four independent variables: Percent Observed Problem Behavior, Behavioral Symptoms Index, Adaptive Skills, and School Problems (see Table 5).

Table 2

Differences in students' age, classroom behavior, and academic performance of pre-intervention using t-Test

\begin{tabular}{|c|c|c|c|c|c|}
\hline Dependent variable & $\begin{array}{c}\text { Intervention } \\
\mu(\mathrm{SD}) \\
N=7^{\mathrm{a}}\end{array}$ & $\begin{array}{c}\text { Comparison } \\
\mu \text { (SD) } \\
N=5\end{array}$ & $\begin{array}{c}\text { Degrees of } \\
\text { freedom }(v)^{\text {a }}\end{array}$ & $\begin{array}{c}t \text {-Test } \\
\text { statistic }\end{array}$ & $\begin{array}{l}\text { Two- } \\
\text { tailed } p\end{array}$ \\
\hline Age & $7.43(.79)$ & $8.80(1.64)$ & 10 & $-1.73^{b}$ & 0.14 \\
\hline \multicolumn{6}{|l|}{ BASC-2 SOS } \\
\hline $\begin{array}{l}\text { Percent Observed Problem } \\
\text { Behavior }\end{array}$ & $52.94(18.60)$ & $32.63(10.86)$ & 10 & 2.17 & $0.06^{*}$ \\
\hline \multicolumn{6}{|l|}{ BASC-2 TRS Percentile Scores } \\
\hline Behavioral Symptoms Index & $91.29(5.56)$ & $73.40(18.58)$ & 10 & $2.09^{b}$ & $0.10^{*}$ \\
\hline Adaptive Skills & $6.43(3.60)$ & $16.20(10.92)$ & 10 & $-1.93^{\mathrm{b}}$ & 0.11 \\
\hline Externalizing Problems & $85.43(14.51)$ & $47.00(23.05)$ & 10 & 3.57 & $0.01^{* * *}$ \\
\hline Internalizing Problems & 43.57 (23.68) & $59.60(24.43)$ & 10 & -1.14 & 0.28 \\
\hline School Problems & $90.57(7.79)$ & $84.20(14.36)$ & 10 & $0.90^{\mathrm{b}}$ & 0.40 \\
\hline \multicolumn{6}{|l|}{ CBM Percentile Scores } \\
\hline Reading & $49.00(28.97)$ & $24.20(19.91)$ & 8 & 1.58 & 0.15 \\
\hline Words Spelled Correctly & 38.38 (39.55) & $24.20(28.98)$ & 7 & 0.62 & 0.55 \\
\hline Math & $57.13(40.23)$ & $38.13(24.18)$ & 6 & 0.81 & 0.45 \\
\hline
\end{tabular}

${ }^{\mathrm{a}}$ Two intervention students refused to complete CBM reading, three intervention students refused to complete CBM writing, and three intervention and one comparison student refused to complete CBM math.

${ }^{\mathrm{b}}$ Equal variances not assumed.

"significant at $\alpha=0.10,{ }^{* * *}$ significant at $\alpha=0.01$

Notes. Data not available for student lost to follow-up in the fall. BASC-2 SOS = Behavior Assessment System for Children, 2nd Ed. Student Observation System (Reynolds \& Kamphaus, 2004); BASC-2 TRS = Behavior Assessment System for Children 2nd Ed. Teacher Rating Scale (Reynolds \& Kamphaus, 2004); CBM = Curriculum-Based Measure (Fewster \& MacMillan, 2002). 
Figure 1

Flowchart of students lost to follow up and students who experienced change at home during the study

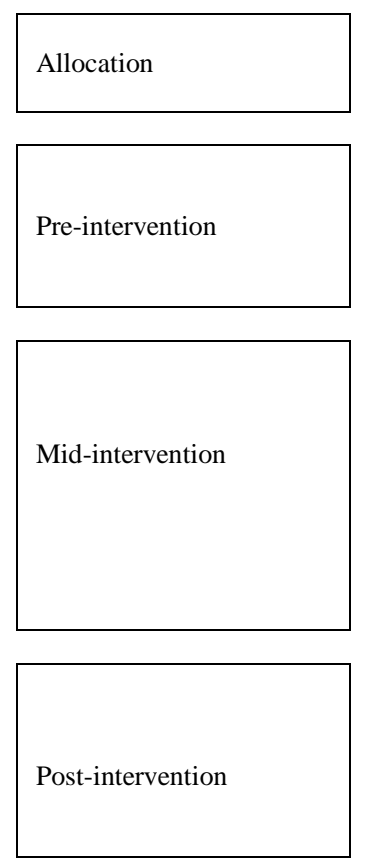

\begin{tabular}{|c|}
\hline $\begin{array}{l}\text { Allocated to comparison group: } \\
n=6 \text { teachers and } n=6 \text { students }\end{array}$ \\
\hline$\vee$ \\
\hline $\begin{array}{l}\text { Lost to follow up due to ill teacher: } n=1 \\
\text { teacher and } n=1 \text { student. }\end{array}$ \\
\hline $\begin{array}{l}\text { Pre-intervention measures on: } \\
n=5 \text { students }\end{array}$ \\
\hline $\boldsymbol{V}$ \\
\hline $\begin{array}{l}\text { Home environment changes: } \\
n=1 \text { student }\end{array}$ \\
\hline $\begin{array}{l}\text { Mid-intervention measures on: } \\
n=5 \text { students }\end{array}$ \\
\hline 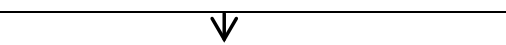 \\
\hline $\begin{array}{l}\text { Home environment changes: } \\
n=1 \text { student continued from mid-interventio }\end{array}$ \\
\hline $\begin{array}{l}\text { Post-intervention measures on: } \\
n=5 \text { students }\end{array}$ \\
\hline
\end{tabular}

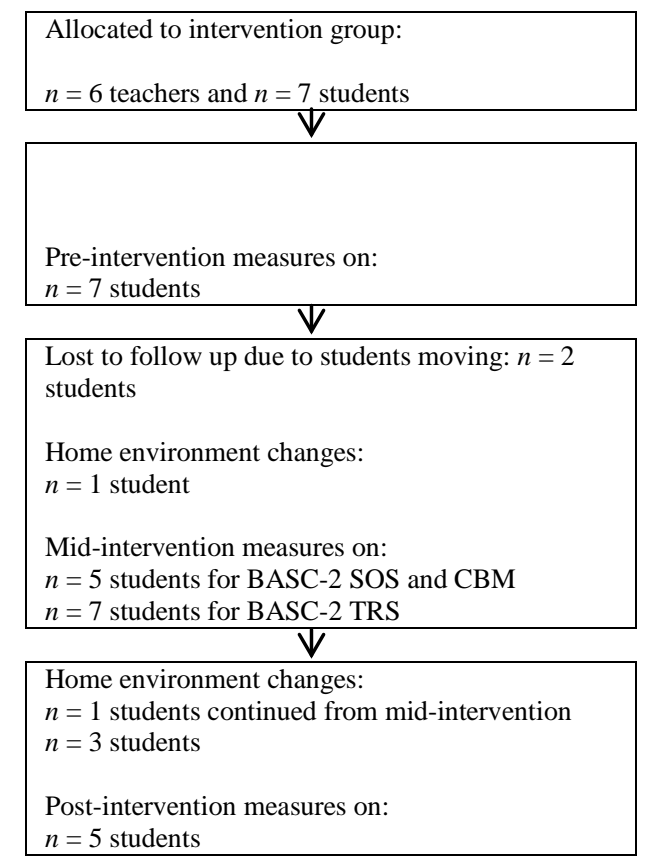

Table 3

Friedman test statistics comparing behavior and academic measures for students pre-, mid-, and post-intervention

\begin{tabular}{|c|c|c|c|c|c|c|}
\hline Dependent Variable & $\begin{array}{c}\text { Pre } \\
\mu \text { (SD) }\end{array}$ & $\begin{array}{c}\text { Mid } \\
\mu \text { (SD) }\end{array}$ & $\begin{array}{c}\text { Post } \\
\mu \text { (SD) }\end{array}$ & $\mathbf{N}$ & $\chi^{2}$ & $p$ \\
\hline \multicolumn{7}{|l|}{ Intervention Group } \\
\hline \multicolumn{7}{|l|}{ BASC-2 SOS } \\
\hline Percent Observed Problem Behavior & $52.94(18.60)$ & $33.86(23.24)$ & $42.90(12.58)$ & 5 & 3.60 & .17 \\
\hline \multicolumn{7}{|l|}{ BASC-2 TRS Percentile Scores } \\
\hline Behavioral Symptoms Index & $91.29(5.56)$ & $86.43(16.52)$ & $87.00(19.74)$ & 5 & 1.41 & .49 \\
\hline Adaptive Skills & $6.43(3.60)$ & $10.43(8.16)$ & $10.00(6.52)$ & 5 & 7.60 & $.02^{* *}$ \\
\hline Externalizing Problems & $85.43(14.51)$ & $82.14(17.27)$ & $84.20(18.62)$ & 5 & 2.00 & .37 \\
\hline Internalizing Problems & $43.57(23.68)$ & $51.29(26.25)$ & $54.00(32.27)$ & 5 & 2.21 & .33 \\
\hline School Problems & $90.57(7.79)$ & $76.71(19.17)$ & $81.80(10.16)$ & 5 & 6.40 & $.04^{* *}$ \\
\hline \multicolumn{7}{|l|}{ CBM Percentile Scores } \\
\hline Reading & $49.00(28.97)$ & $41.50(29.93)$ & $45.00(29.37)$ & 5 & 1.60 & .45 \\
\hline Math & $57.13(40.23)$ & $49.00(42.89)$ & $41.00(38.71)$ & 4 & 1.50 & .47 \\
\hline Words Spelled Correctly & 38.38 (39.55) & $45.00(36.95)$ & $54.70(48.76)$ & 4 & .14 & .93 \\
\hline \multicolumn{7}{|l|}{ Comparison group } \\
\hline \multicolumn{7}{|l|}{ BASC-2 SOS } \\
\hline Percent Observed Problem Behavior & $32.63(10.85)$ & $32.29(11.20)$ & $30.01(17.34)$ & 5 & .40 & .82 \\
\hline \multicolumn{7}{|l|}{ BASC-2 TRS Percentile Scores } \\
\hline Behavioral Symptoms Index & $73.40(18.58)$ & $78.40(16.29)$ & 80.20 (20.77) & 5 & 1.60 & .45 \\
\hline Adaptive Skills & $16.52(10.92)$ & $18.40(15.14)$ & $15.20(12.21)$ & 5 & 2.21 & .33 \\
\hline Externalizing Problems & $47.00(23.05)$ & $48.60(26.70)$ & 62.40 (37.09) & 5 & 2.21 & .33 \\
\hline Internalizing Problems & $59.60(24.43)$ & $56.60(31.82)$ & $64.20(27.98)$ & 5 & 1.00 & .61 \\
\hline School Problems & $84.20(14.36)$ & 76.71 (19.17) & $81.8(10.16)$ & 5 & .11 & .95 \\
\hline \multicolumn{7}{|l|}{ CBM Percentile Scores } \\
\hline Reading & $24.20(19.91)$ & $28.75(5.95)$ & $23.20(14.98)$ & 4 & .00 & 1.00 \\
\hline Math & $38.13(24.18)$ & $30.63(33.50)$ & 20.00 (23.98) & 3 & 2.67 & .26 \\
\hline Words Spelled Correctly & $24.20(28.98)$ & $19(20.26)$ & $15.50(22.73)$ & 4 & .13 & .94 \\
\hline
\end{tabular}

${ }^{* *}$ significant at $\alpha=0.05$

Note. Students with missing data excluded from analysis. Some students refused to complete parts of the CBM. BASC-2 SOS = Behavior Assessment System for Children $2^{\text {nd }}$ Ed. Student Observation System (Reynold \& Kamphaus, 2004); BASC-2 TRS = Behavior Assessment System for Children $2^{\text {nd }}$ Ed. Teacher Rating Scale (Reynold \& Kamphaus, 2004); CBM = Curriculum Based Measure (Fewster \& MacMillan, 2002). 
Academic achievement did not show statistically significant change (see Table 3).

\section{Figure 2}

Mean percentile score for BASC-2 TRS Adaptive Skill Scale grouped by experimental group to show direction of change in Friedman analysis

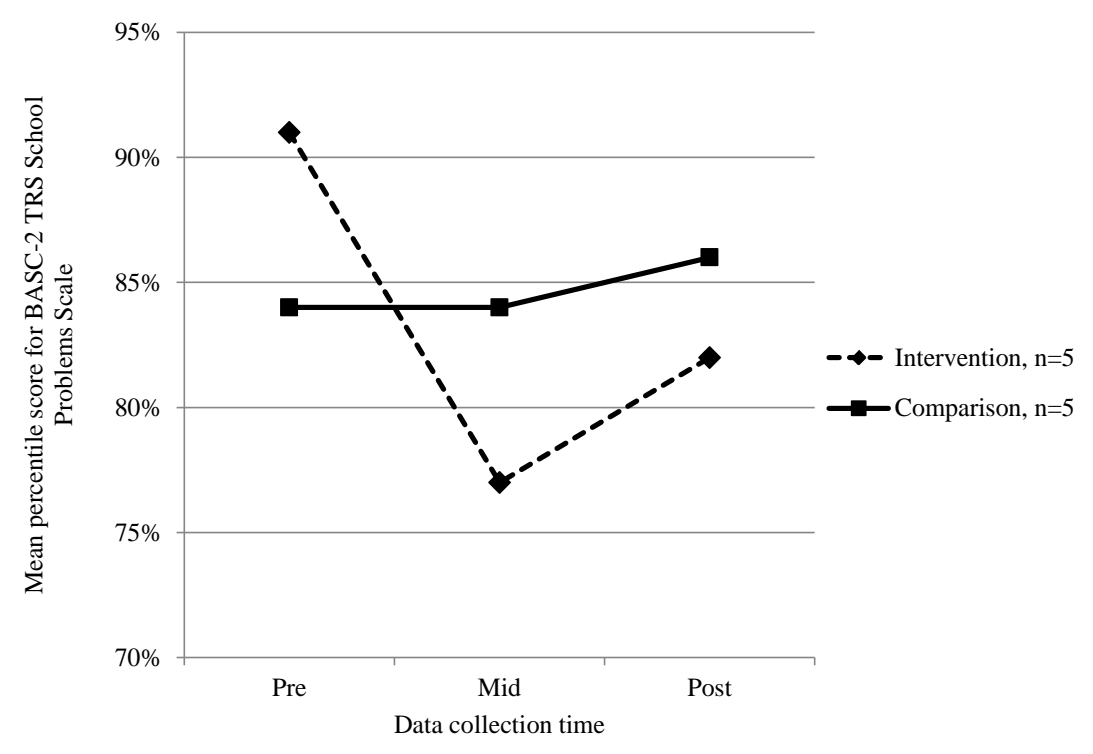

\section{Figure 3}

Mean percentile scores for BASC-2 TRS School Problem Scale grouped by experimental group to show direction of change in Friedman analysis

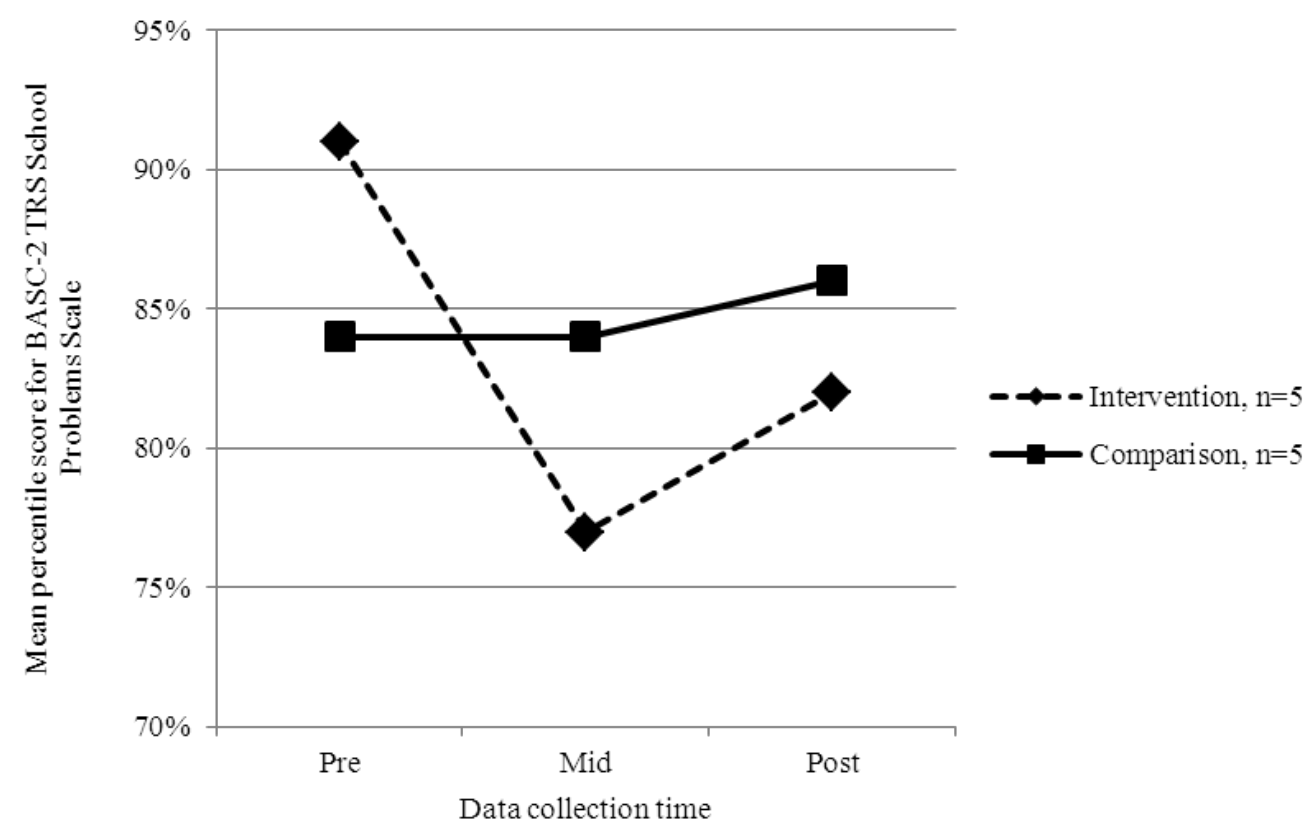


Table 4

Post-hoc analysis of Friedman test for statistically significant intervention group BASC-2 TRS scales for students with FASD

\begin{tabular}{|c|c|c|c|c|c|c|c|}
\hline & \multicolumn{3}{|c|}{ Mean Rank } & \multirow{2}{*}{$\mathbf{k}$} & \multirow{2}{*}{$\mathbf{N}$} & \multirow{2}{*}{$\mathbf{z}$} & \multirow{2}{*}{$\mathbf{p}$} \\
\hline & Pre & Mid & Post & & & & \\
\hline Adaptive Skills Percentile & 1.30 & $2.80^{*}$ & 1.90 & 3 & 5 & 1.34 & .09 \\
\hline School Problems Percentile & 2.80 & $1.20^{*}$ & 2.00 & 3 & 5 & 1.35 & .09 \\
\hline
\end{tabular}

* significantly different from pre-intervention at $\alpha=0.10$

Table 5

Effect size for intervention group students pre- to post-intervention

\begin{tabular}{lcc}
\hline Outcome measure & Cohen's d $^{\mathbf{a}}$ & Direction of change \\
\hline BASC-2 SOS Percent observed problem behavior & 0.54 & 0.77 \\
BASC-2 TRS Behavioral symptoms index percentile & 0.99 & improved \\
BASC-2 TRS Adaptive skills percentile & 0.09 & improved \\
BASC-2 TRS Externalizing problems percentile & 0.44 & improved \\
BASC-2TRS Internalizing problems percentile & 1.13 & declined improved \\
BASC-2 TRS School problems percentile & 0.14 & declined \\
CBM Reading percentile & 0.41 & improved \\
CBM Words spelled correctly percentile & 0.40 & declined \\
CBM Math & &
\end{tabular}

${ }^{\mathrm{a}}$ Equation 13 Morris and DeShon, 2002

Note. Students with missing data excluded from analysis. BASC-2 SOS = Behavior Assessment System for Children $2^{\text {nd }}$ Ed. Student Observation System (Reynold \& Kamphaus, 2004); BASC-2 TRS = Behavior Assessment System for Children $2^{\text {nd }}$ Ed. Teacher Rating Scale (Reynold \& Kamphaus, 2004); CBM = Curriculum-Based Measure (Fewster \& MacMillan, 2002).

\section{Qualitative description findings}

Inductive thematic analysis of the teachers' interviews yielded three themes: importance of the PD program; change in behavior perception; and strategies for students with FASD.

Importance of the professional development program. Intervention teachers believed the professional development program impacted their teaching practice. Program length, mentoring, and use of the LEIC tool were highlighted as important features, although all parts of the program were valued. Intervention teacher A commented: "Every time, I learned new things that I can incorporate." Spreading the PD program over the school year helped intervention teachers incorporate the training into their daily practice. Intervention teacher B stated, "I think [spreading out the program] was very effective. Rather than trying to fit it all into the fall . . . then you might be floundering or falling back or forgetting." The intervention teachers appreciated the mentor. Intervention teacher $\mathrm{C}$ noted: "[The mentor] had good suggestions and was really supportive and not critical." All intervention teachers highlighted the LEIC tool as invaluable to developing accommodations applicable to the everyday complexity of their classrooms. One intervention teacher explained:

[Information] in the files was very useful in terms of background but didn't give a lot of really useful things that would work down on the ground on a day-to-day basis in the classroom . . . Just having the LEIC page the way it was set out was good because I wouldn't have thought of all those things to include and really trying to build on strengths. (Intervention teacher A)

Intervention teachers were unanimous that the PD program improved their ability to accommodate students with FASD in their classrooms.

Perceptions of classroom behavior. Changes in behavior perception were identified as an important outcome of the PD program. One teacher described how her understanding of underlying neurological impairment altered her response to problem behavior:

I remember when $\mathrm{S}$ first came into the classroom, he wasn't listening and I was getting very firm with him and he just huddled up ...I just thought he was being a jerk... but he was trying. Now we understand that, so we leave it. (Intervention teacher B)

Intervention teacher D stated, "It reminded me to slow down, think about the child, be patient, and realize that he can't help it." Intervention teachers valued their new perspective on problem behavior and how it changed their responses.

Strategies for students with FASD. All teachers described their appreciation for students' strengths; 
however, intervention teachers indicated they were very purposeful in leveraging those strengths and confident in developing accommodations. Intervention teacher $\mathrm{C}$ had a student with excellent penmanship who needed extra time to process instructions. She gave her class paper stoplights to indicate their progress in a lesson and began displaying examples of good penmanship. This accommodation allowed the student with FASD to complete her work without being singled out, and reinforced the value of her work. In contrast, comparison teacher A stated, "I don't know that much in terms of FASD and what the best strategies to use with kids are." Intervention teachers used a variety of accommodations; comparison teachers identified challenges in developing accommodations (see Table 6).

Table 6

Examples of classroom environment accommodations

\begin{tabular}{|c|c|c|}
\hline Environment & Instruction & Curriculum \\
\hline Seat student near teacher for group work & $\begin{array}{l}\text { Blunt, simple directions given one at a } \\
\text { time }\end{array}$ & $\begin{array}{l}\text { Provide as many hands-on opportunities as } \\
\text { possible }\end{array}$ \\
\hline $\begin{array}{l}\text { Gadgets to decrease sensory stimuli, e.g., } \\
\text { earphones or hat }\end{array}$ & $\begin{array}{l}\text { Prepare student for transitions to next } \\
\text { activity }\end{array}$ & One-to-one sharing with classroom peers \\
\hline $\begin{array}{l}\text { Provide opportunities to leave desk when } \\
\text { becomes fidgety during seat work }\end{array}$ & $\begin{array}{l}\text { Provide extra time to process instructions } \\
\text { and complete work }\end{array}$ & $\begin{array}{l}\text { Provide assistive software and/or a scribe for } \\
\text { writing }\end{array}$ \\
\hline Provide fidget toys & Repeat instructions & Model language skills \\
\hline
\end{tabular}

\section{Discussion}

There were four principal findings: teachers were satisfied with the PD program; there was no statistically significant change in observed behaviors of intervention students; teachers reported more positively on student behavior; and there was no statistically significant change in academic achievement. Given the lack of research regarding effects of PD programs on teachers of students with FASD and on these students, it is important to report these findings in spite of study limitations.

Behavior observed by research staff did not demonstrate a statistically significant change; however, the effect size was greater than .50 (see Table 5). The effect size suggests that the sample size was inadequate to detect change in the BASC-2 SOS measure.

The statistically significant changes in Adaptive Skills and School Problems represent meaningful changes in students' behavior. When teachers perceive students are more attentive, motivated to learn, and better able to perform daily living skills, they are more likely to interact with them in a positive manner, which may lead to better student-teacher relationships (Pianta \& Walsh, 1996).

Statistically significant changes were not observed for academic achievement; this could be due to the changes that happened within the intervention group or insufficient follow-up time. The intervention group was small and all but one intervention student experienced changes in their home environment at mid- or post-intervention (see Figure 1) which may have limited our ability to detect statistically significant changes.
In our intervention, teachers were taught to reframe behaviors associated with FASD as neurodevelopmental disability rather than willful disobedience. This is consistent with the work of Bertrand (2009), who found positive results from parents' reactions to their children with FASD in the home environment. It is possible that, with a larger sample, we would see results similar to Bertrand (2009) in the school setting. Further work could validate the intervention in a larger population. Future interventions could examine changes by parents and teachers in both home and school settings respectively.

\section{Limitations}

Generalizability of findings to other populations of students with FASD are limited by the small sample size, nonequivalent groups, homogeneity of teachers, and use of only one mentor working with a group of experienced, female Caucasian teachers. Having one mentor allows for consistency for research purposes; however, the results might be attributed to the mentor's or intervention teachers' unique skill sets. Intervention group improvements could be due to regression towards the mean, because groups were non-equivalent pre-intervention.

\section{Acknowledgements}

This study would not have been possible without support from the Victoria Foundation, POPFASD, and the students, staff, and administration of School District No. 57. Pearson provided a discount on the BASC-2. 


\section{References}

Bertrand, J. (2009). Interventions for children with fetal alcohol spectrum disorders (FASDs): Overview of findings for five innovative research projects. Research in Developmental Disabilities: A Multidisciplinary Journal, 30, 986-1006. doi: 10.1016/j.ridd.2009.02.003

Burden, M. J., Jacobson, S. W., \& Jacobson, J. L. (2005). Relation of prenatal alcohol exposure to cognitive processing speed and efficiency in childhood. Alcoholism: Clinical and Experimental Research, 29, 1473-1483. doi:10.1097/01.alc.0000175036.34076.a0

Burden, M. J., Jacobson, S. W., Sokol, R. J., \& Jacobson, J. L. (2005). Effects of prenatal alcohol exposure on attention and working memory at 7.5 years of age. Alcoholism: Clinical and Experimental Research, 29, 443-452. doi:10.1097/01.ALC.0000156125.50577. EC

Burstyn, I., Sithole, F., \& Zwaigenbaum, L. (2010). Autism spectrum disorders, maternal characteristics and obstetric complications among singletons born in Alberta, Canada. Chronic Diseases in Canada, 30, 125-134. Retrieved from http://www.phac-aspc.gc.ca/ publicat/cdic-mcbc/index-eng.php

Chudley, A. E., Conry, J., Cook, J. L., Loock, C., Rosales, T., \& LeBlanc, N. (2005). Fetal alcohol spectrum disorder: Canadian guidelines for diagnosis [Supplement material]. Canadian Medical Association Journal, 172, S1-S2. doi:10.1503/ cmaj.1040302

Clark, E. (2012). Assessment of a school-based intervention for elementary school students diagnosed with Fetal Alcohol Spectrum Disorder (FASD). (Doctoral dissertation). Retrieved from https://circle. ubc.ca/handle/2429/42251.

Cook, T. D., \& Campbell, D. T. (1979). Quasiexperimentation: Design \& analysis issues for field settings. Boston, MA: Houghton Mifflin Company.

Ellis, P. (2010). The essential guide to effect sizes: Statistical power, meta-analysis, and the interpretation of research results. Cambridge, UK: Cambridge University Press.

Fewster, S., \& MacMillan, P. (2002). School-based evidence for the validity of curriculum-based measurement of reading and writing. Remedial and Special Education, 23, 149-156. doi:10.1177/ 07419325020230030301

Gessner, B., Bischoff, H., Perham-Hester, K., Chandler, B., \& Middaugh, J. (1998). The educational attainment of children with fetal alcohol syndrome. State of Alaska Epidemiology Bulletin: Recommendations and Reports, 2, 1-14. Retrieved from http://www.epi. hss.state.ak.us/bulletins/bltnidx.jsp

Greene, J. C., Caracelli, V. J., \& Graham, W. F. (1989). Toward a conceptual framework for mixed-method evaluation designs. Educational Evaluation and Policy Analysis, 11(3), 255-274. doi:10.3102/01623737 011003255

Guba, E.G., \& Lincoln, Y.S. (1989). Judging the quality of fourth generation evaluation. In E. G. Guba \& Y. S. Lincoln (Eds.), Fourth generation evaluation (pp.
228-251). Newbury Park, CA, United States: Sage Publications, Inc.

Health Canada. (2002). Congenital anomalies in CanadaA perinatal health report. Ottawa: Minister of Public Works and Government Services Canada. Retrieved from http://www.publications.gc.ca/site/eng/home. html

Hintz, J., Shapiro, E., Conte, K., \& Basile, I. (1997). Oral reading fluency and authentic reading material: Criterion validity of the technical features of CBM survey-level assessment. School Psychology Reviews, 26, 535-553.

Kable, J. A., \& Coles, C. D. (2004). The impact of prenatal alcohol exposure on neurophysiological encoding of environmental events at six months. Alcoholism: Clinical and Experimental Research, 28, 489-496. doi:10.1097/01.ALC.0000117837.66107.64

Kaemingk, K. L., \& Halverson, P. T. (2000). Spatial memory following prenatal alcohol exposure: More than a material specific memory deficit. Child Neuropsychology: A Journal on Normal and Abnormal Development in Childhood and Adolescence, 6, 115-128. doi:10.1076/chin.6.2.115. 7058

Malbin, D. (2006). Findings from the FASCETS Oregon fetal alcohol project: Efficacy of a neurobehavioral construct: Interventions for children and adolescents with fetal alcohol spectrum disorders (FASD). Retrieved from http://www.fascets.org/index.html.

Mattson, S. N., \& Roebuck, T. M. (2002). Acquisition and retention of verbal and nonverbal information in children with heavy prenatal alcohol exposure. Alcoholism: Clinical and Experimental Research, 26, 875-882. doi:10.1111/j.1530-0277.2002. tb02617.x

May, P., Gossage, P., Marais, A., Adnams, C., Hoyme, H., Jones, K, . . V Viljoen, D. (2007). The epidemiology of fetal alcohol syndrome and partial FAS in a South African community. Drug and Alcohol Dependence, 88, 259-271. doi:10.1016/j.drugalcdep.2006.11.007

McGee, C. L., Fryer, S. L., Bjorkquist, O. A., Mattson, S. N., \& Riley, E. P. (2008). Deficits in social problem solving in adolescents with prenatal exposure to alcohol. The American Journal of Drug and Alcohol Abuse, 34, 423-431. doi:10.1080/0095299080212 2630

McMaster, K., \& Espin, C. (2007). Technical features of curriculum-based measurement in writing. The Journal of Special Education, 41, 68-94. doi:10.1177/00224669070410020301

Miles, M. B., \& Huberman, A. M. (1994). Qualitative data analysis: An expanded sourcebook (2nd ed.). Thousand Oaks, CA, United States: Sage.

Morris, S., \& DeShon, R. (2002). Combining effect size estimates in meta-analysis with repeated measures and independent-groups designs. Psychological Methods, 7, 105-125. doi:10.1037/1082-989X.7.1. 105

Pianta, R. C., \& Walsh, D. J. (1996). High-risk children in schools: Constructing sustaining relationships. New York, NY, United States: Routledge.

Reynolds, C. R., \& Kamphaus, R. W. (2004). Behavior assessment system for children, second edition 
manual. Circle Pines, MN, United States: AGS Publishing.

Sandelowski, M. J. (2000). Whatever happened to qualitative description? Research in Nursing \& Health, 23, 334-340. doi:10.1002/1098-240X (200008)

Siegel, S., \& Castellan, J. (1988). The Friedman two-way analysis of variance by ranks. Nonparametric statistics for the behavioral sciences (2nd ed., pp. 174-184). New York, NY, United States: McGraw-Hill Inc.

Sokol, R. J., \& Clarren, S.K. (1989). Guidelines for use of terminology describing the impact of prenatal alcohol on the offspring. Alcoholism: Clinical and Experimental Research, 13, 597-598.

Streissguth, A. P., Barr, H. M., \& Sampson, P. D. (1990). Moderate prenatal alcohol exposure: Effects on child IQ and learning problems at age $7 \quad 1 / 2$ years. Alcoholism: Clinical and Experimental Research, 14, 662-669. doi:10.1111/j.1530-0277.1990.tb01224.x

Tan, C. (2007). Test review: Behavioral assessment system for children (2nd ed.). Assessment for Effective Intervention, 32, 121-124. doi:10.1177/153450840 70320020301

Wayman, M., Wallace, T., Wiley, H., Tichá, R., \& Espin, C. (2007). Literature synthesis on curriculum-based measurement in reading. The Journal of Special Education, 41, 85-120. doi:10.1177/00224669070 410020401 